\title{
Identification of hybrids between triticale and Aegilops juvenalis (Thell.) Eig and determination of genetic similarity with ISSRs
}

\author{
A. Gradzielewska, D. Gruszecka, J. Leśniowska-Nowak and \\ E. Paczos-Grzęda \\ Institute of Plant Genetics, Breeding and Biotechnology, \\ University of Life Sciences in Lublin, Lublin, Poland \\ Corresponding author: A. Gradzielewska \\ E-mail: agnieszka.gradzielewska@up.lublin.pl
}

Genet. Mol. Res. 11 (3): 2147-2155 (2012)

Received September 26, 2011

Accepted February 8, 2012

Published July 10, 2012

DOI http://dx.doi.org/10.4238/2012.July.10.1

\begin{abstract}
Wide hybridization expands the gene pool of cultivated species and can produce genotypes with practical value, often resistant to diseases. In plants, ISSRs are often used for hybrid identification as well as for diversity evaluation. We estimated genetic similarity among advanced genetic stocks of triticale hybrids and identified Aegilops juvenalis introgressions into triticale. Fourteen ISSR primers amplified from 12 to 23 DNA fragments. The number of polymorphic products per primer ranged from three to nine, with a mean of 5.1. The polymorphic information content values ranged from 0.39 to 0.66 , with a mean of 0.52 . Thirteen primers amplified products indicating presence of $A$. juvenalis chromatin. The largest mean genetic similarity (0.84) with all other forms was shown by a strain derived from an $A$. juvenalis $6 \mathrm{x} \times[($ Lanca $\times$ L506/79 $) \times$ CZR142/79] hybrid, while $A$. juvenalis was the least similar (0.33). We conclude that ISSRs can reliably identify $A$. juvenalis chromatin in the triticale background and efficiently estimate genetic similarity of hybrids and parental forms.
\end{abstract}

Key words: Genetic similarity; Triticale; Hybrids; Aegilops juvenalis; ISSR 


\section{INTRODUCTION}

Hexaploid triticale (x Triticosecale Wittmack), just as its rye parent, is resistant to abiotic stresses, such as frost and drought (Goyali et al., 2002; Woś et al., 2002). For many years, triticale was also one of the most resistant cereals to diseases, but in many instances, resistance has been broken by wheat or rye pathogens. Still, the disease symptoms tend to be milder relative to the parents (Zamorski and Schollenberger, 1995; Góral, 2006).

Crop resistance to stresses, both biotic and abiotic, can be improved by the introduction of genes from wild relatives. Moreover, wide hybridization expands the genetic diversity of a crop species, giving rise to new genotypes that may be of practical value (Gruszecka, 1998; Gradzielewska, 2006a,b; Vaccino et al., 2010).

Triticale's genetic diversity can be extended by hybridization with wild Triticeae, including Aegilops species, which carry resistance genes to fungal pathogens, such as leaf and stem rusts, powdery mildew, take-all, and numerous pests (nematodes and insects), as well as abiotic stresses such as drought, cold, frost, salinity, low soil $\mathrm{pH}$ and high soil aluminum levels (Kimber and Feldman, 1987; Holoubec et al., 1992, 1993; Masłowski et al., 1997). Earlier studies have shown that some qualitative and quantitative traits of triticale were improved in hybrids with Aegilops (Gruszecka, 1998; Gruszecka and Kowalczyk, 2002; Gruszecka et al., 2004).

Molecular markers are often used by plant breeders for diversity evaluation within or between populations, as well as for hybrid identification. In plants, the inter-simple sequence repeat (ISSR) technique is widely employed for analyses of genetic diversity (Ziętkiewicz et al., 1994; Reddy et al., 2002). These markers have been applied for polymorphism investigations in rye (Matos et al., 2001; Bolibok et al., 2005), wheat (Nagaoka and Ogihara, 1997), barley (Fernandez et al., 2002), and maize (Kantety et al., 1995).

In triticale, ISSR showed little polymorphism among cultivars, but still, the method was more effective than RAPD (random amplified polymorphic DNA) (Gonzales et al., 2002; Stojałowski and Góral, 2002; Tams et al., 2002). The ISSRs were shown to be effective in the development of the sequence-characterized amplified region markers and useful for detection of rye chromosome fragments in the triticale background (Vaillancourt et al., 2008).

The goal of this study was to estimate genetic similarity among hybrids of hexaploid triticale with Aegilops juvenalis (Thell.) Eig and the parental forms and to detect and confirm the presence of the wild parent's DNA among the hybrid derivatives.

\section{MATERIAL AND METHODS}

The material for this study consisted of seven advanced strains of hexaploid triticale derived from hybrids with A. juvenalis (Thell.) Eig, and the parents themselves. The $\mathrm{F}_{1}$ hybrids of triticale with Aegilops were backcrossed two or four times to the triticale parent and subsequently self-pollinated (Table 1). The accession of A. juvenalis used here was obtained from the collection of the Institute of Plant Genetics and Crop Plant Research (IPK), Gatersleben, Germany.

Total genomic DNA was extracted from the coleoptiles of several-day-old seedlings, following the method of Milligan (1992), while ISSR analyses were conducted as described by Ziętkiewicz et al. (1994), with modifications. Fourteen primers were used (Table 2) selected from a group of 40 primers tested in two replications per genotype. For each primer, a negative control reaction with double-distilled water was included. 


\begin{tabular}{|c|c|c|c|c|}
\hline & No. of the strain & Designation & Generation & Pedigree \\
\hline \multirow[t]{4}{*}{ Combination 1} & 1 & CZR350/9 & $\mathrm{B}_{4} / \mathrm{F}_{7}$ & \multirow[t]{4}{*}{$\begin{array}{l}\text { Aegilops juvenalis } 6 \mathrm{x} \times[(\text { Lanca } \times \text { L506/79) } \mathrm{x} \\
\text { CZR142/79] }\end{array}$} \\
\hline & 2 & CZR350/833/3/95 & $\mathrm{B}_{2} / \mathrm{F}_{9}$ & \\
\hline & 3 & CZR350/833/3/95 & $\mathrm{B}_{2} / \mathrm{F}_{9}$ & \\
\hline & 4 & CZR350/833/3/95 & $\mathrm{B}_{2} / \mathrm{F}_{9}$ & \\
\hline \multirow[t]{3}{*}{ Combination 2} & 5 & CZR700/9 & $\mathrm{B}_{2}^{2} / \mathrm{F}_{8}$ & \multirow[t]{3}{*}{ [(Jana $\mathrm{x}$ Tempo $) \mathrm{x}$ Jana $] \mathrm{x}$ Aegilops juvenalis $6 \mathrm{x}$} \\
\hline & 6 & CZR700/VI/4/1/01 & $\mathrm{B}_{2} / \mathrm{F}_{4}$ & \\
\hline & 7 & CZR700/VIII/1/3/01 & $\mathrm{B}_{2} / \mathrm{F}_{2}$ & \\
\hline \multicolumn{5}{|l|}{ Parental forms } \\
\hline \multirow[t]{2}{*}{ Combination 1} & $\mathrm{Aj}$ & \multirow{4}{*}{$\begin{array}{l}\text { + Aegilops juvenalis (Thell.) Eig } \\
\text { (Lanca } \mathrm{x} \text { L506/79) x CZR142/79 } \\
\text { क (Jana } \mathrm{x} \text { Tempo) x Jana } \\
\text { Aegilops juvenalis (Thell.) Eig }\end{array}$} & & \\
\hline & A & & & \\
\hline Combination 2 & B & & & \\
\hline & $\mathrm{Aj}$ & & & \\
\hline
\end{tabular}

The total reaction volume was $15 \mu \mathrm{L}$ and contained $1 \mathrm{X}$ PCR buffer with $\left(\mathrm{NH}_{4}\right)_{2} \mathrm{SO}_{4}$ (75 mM Tris, $\mathrm{pH} 8.8,20 \mathrm{mM}\left(\mathrm{NH}_{4}\right)_{2} \mathrm{SO}_{4}, 0.01 \%$ Tween 20; Fermentas), $1.5 \mathrm{mM} \mathrm{MgCl} 2,160$ $\mu \mathrm{M}$ of each dNTP, $0.47 \mu \mathrm{M}$ primer, $40 \mathrm{ng}$ DNA template and $0.5 \mathrm{U}$ Taq DNA Polymerase (Fermentas), run on the T1 thermocycler (Biometra). The cycling pattern was primer-specific. For SR16, SR27, SR28, SR31, SR37, and SR38, the thermal profile was initial denaturation at $95^{\circ} \mathrm{C}$ for $7 \mathrm{~min}$, followed by 38 cycles of denaturation at $95^{\circ} \mathrm{C}$ for $30 \mathrm{~s}$, annealing for $45 \mathrm{~s}$ with the temperature for the first 3 cycles being $54^{\circ} \mathrm{C}, 53^{\circ} \mathrm{C}$ for the next 3 cycles, and $52^{\circ} \mathrm{C}$ for the remaining 32 cycles, and extension at $72^{\circ} \mathrm{C}$ for $2 \mathrm{~min}$. The last cycle was followed by a final incubation for $7 \mathrm{~min}$ at $72^{\circ} \mathrm{C}$. For SR14, SR17, SR23, and SR34 annealing was as follows: the first 3 cycles at $57^{\circ} \mathrm{C}$, the following 3 cycles at $56^{\circ} \mathrm{C}$ and remaining cycles at $55^{\circ} \mathrm{C}$. For SR 33 , the annealing temperatures were $52^{\circ}, 51^{\circ}$ and $50^{\circ} \mathrm{C}$, respectively.

The amplification products were loaded onto a $2 \%$ agarose gel with $0.01 \%$ ethidium bromide and run in TBE buffer ( $89 \mathrm{mM}$ Tris-borate, $2.5 \mathrm{mM}$ EDTA) for $2 \mathrm{~h}$ at $120 \mathrm{~V}$. The fragment sizes were determined relative to the GeneRuler ${ }^{\mathrm{TM}}$ 100-bp DNA Ladder Plus (Fermentas). Separated DNA fragments were visualized under UV light and photographed.

Based on the results obtained, the indices - the polymorphism information content (PIC) (Nei, 1973) and the assay efficiency index (AEI, mean number of polymorphic fragments) (Pejic et al., 1998) - of the ISSR method were calculated. Each band was considered an ISSR locus, and only reproducible bands were scored for the construction of binary matrices. ISSR bands with the same molecular weight were considered to be the same locus. The data matrix was used to calculate the genetic similarity (GS) index between pairs of all genotypes analyzed, using the Dice formula (Nei and Li, 1979). Genetic relationships were estimated using the unweighted pair-group method with arithmetic mean (UPGMA) cluster analysis based on the GS indices. The NTSYS-pc 2.10q software was used for calculations (Rohlf, 2001).

\section{RESULTS}

The 14 primers used amplified a total number of 240 DNA fragments of various sizes. The number of fragments amplified per primer ranged from 12 (SR38) to 23 (SR16) (Table 2), averaging 17.1 per primer. Of the total of 240 fragments, $72(30 \%)$ were polymorphic (Table 2). On average, a single primer generated between three (SR17, SR34, SR36, SR38) and nine (SR14, SR16) polymorphic fragments, and the AEI index was calculated at 5.1. The values 
of the PIC of the ISSR method ranged from 0.39 to 0.66 , with an average of 0.52 (Table 2).

Of the 14 primers, 13 amplified fragments specific for A. juvenalis (Tables 2 and 3). These products confirmed the presence of A. juvenalis DNA in triticale. The reaction carried out with two primers (SR17 and SR23) allowed the identification of wild species DNA in all seven strains investigated. Overall, A. juvenalis DNA was identified by four to eleven specific ISSR fragments (Table 3 ). On the other hand, all 14 primers tested amplified 72 products in $A$. juvenalis itself. These fragments were considered specific to this wild species (Table 2).

\begin{tabular}{|c|c|c|c|c|c|c|c|c|}
\hline \multirow[t]{2}{*}{ Primer } & \multirow[t]{2}{*}{ Sequence } & \multicolumn{4}{|c|}{ Number of bands } & \multirow[t]{2}{*}{ PIC } & \multicolumn{2}{|c|}{ Band size range (bp) } \\
\hline & & Total & Polymorphic & $\begin{array}{l}\text { From Aegilops } \\
\text { juvenalis }\end{array}$ & $\begin{array}{c}\text { Specific only for } \\
\text { A. juvenalis }\end{array}$ & & Total & Polymorphic \\
\hline SR14 & $(\mathrm{GA})_{7} \mathrm{YG}$ & 21 & 9 & 1 & 6 & 0.61 & $180-2050$ & $180-2050$ \\
\hline SR16 & $(\mathrm{GA}) \mathrm{C}$ & 23 & 9 & 3 & 5 & 0.50 & $260-1570$ & $260-900$ \\
\hline SR17 & $(\mathrm{GA})_{8}^{8} \mathrm{YC}$ & 16 & 3 & 1 & 6 & 0.59 & $210-1210$ & $640-710$ \\
\hline SR22 & $(\mathrm{CA})_{8}^{8} \mathrm{G}$ & 15 & 5 & 1 & 3 & 0.55 & $480-1830$ & $560-1830$ \\
\hline SR23 & $(\mathrm{CA})_{8}^{8} \mathrm{GC}$ & 18 & 6 & 1 & 6 & 0.61 & $310-1880$ & $530-1880$ \\
\hline SR27 & $(\mathrm{TC})_{8} \mathrm{G}$ & 18 & 8 & 2 & 6 & 0.62 & $400-1710$ & $400-1710$ \\
\hline SR28 & $(\mathrm{TG})_{8} \mathrm{G}$ & 17 & 4 & 2 & 4 & 0.49 & $310-1700$ & $460-1450$ \\
\hline SR31 & $(\mathrm{AG})_{8}^{8} \mathrm{YC}$ & 15 & 4 & 1 & 7 & 0.66 & $210-1410$ & $320-1270$ \\
\hline SR32 & $(\mathrm{AG})_{8}^{8} \mathrm{YT}$ & 16 & 5 & 1 & 5 & 0.51 & $300-1860$ & $460-1170$ \\
\hline SR33 & $(\mathrm{AG})_{8}^{8} \mathrm{~T}$ & 17 & 6 & 2 & 5 & 0.53 & $360-1650$ & $460-1020$ \\
\hline SR34 & $(\mathrm{TC})_{8} \mathrm{CC}$ & 17 & 3 & 0 & 6 & 0.44 & $430-2400$ & $700-1600$ \\
\hline SR36 & $(\mathrm{AC})_{8}^{8} \mathrm{CG}$ & 19 & 3 & 2 & 7 & 0.51 & $480-2540$ & $580-1070$ \\
\hline SR37 & $(\mathrm{AC})_{8}^{8} \mathrm{C}$ & 16 & 4 & 3 & 3 & 0.39 & $470-1280$ & $780-1280$ \\
\hline SR38 & $(\mathrm{CT})_{8} \mathrm{G}$ & 12 & 3 & 2 & 3 & 0.49 & $420-1780$ & $620-1010$ \\
\hline Sum/size range & - & 240 & 72 & 22 & 72 & - & $180-2540$ & $180-2050$ \\
\hline Mean & - & 17.1 & 5.1 & 1.6 & 5.1 & 0.52 & - & \\
\hline
\end{tabular}

PIC = polymorphic information content.

\begin{tabular}{|c|c|}
\hline Hybrid & Band size $[\mathrm{bp}]$ \\
\hline & $\mathrm{SR} 23^{1880} \mathrm{SR} 28^{1445} \mathrm{SR} 32^{860} \mathrm{SR} 37^{1170}$ \\
\hline & 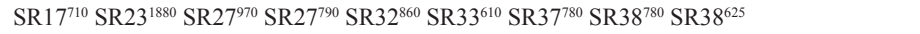 \\
\hline & SR17 $7^{110} \mathrm{SR} 23^{1880} \mathrm{SR} 27^{970} \mathrm{SR} 27^{790} \mathrm{SR} 32^{860} \mathrm{SR} 33^{610} \mathrm{SR} 36^{670} \mathrm{SR} 37^{1280} \mathrm{SR} 37^{1170} \mathrm{SR} 37^{780} \mathrm{SR} 38^{780}$ \\
\hline 4 & 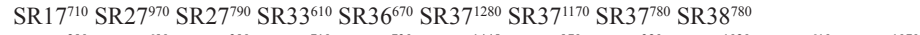 \\
\hline & SR14 ${ }^{290} \mathrm{SR} 16^{600} \mathrm{SR} 16^{6^{390}} \mathrm{SR} 17^{710} \mathrm{SR} 22^{7^{730}} \mathrm{SR} 28^{1445} \mathrm{SR} 28^{970} \mathrm{SR} 31^{320} \mathrm{SR} 33^{1020} \mathrm{SR} 33^{610} \mathrm{SR} 36^{1070}$ \\
\hline & SR16 $6^{620}$ SR1 $17^{710}$ SR22 $2^{730}$ SR2 $8^{1445}$ SR31 $1^{320}$ SR3 $6^{670}$ SR33 $3^{1020}$ SR $33^{610}$ \\
\hline & SR14 ${ }^{290} \mathrm{SR} 16^{6^{220}} \mathrm{SR} 16^{6^{390}} \mathrm{SR} 17^{710} \mathrm{SR} 22^{7^{730}} \mathrm{SR} 28^{1445} \mathrm{SR} 28^{970} \mathrm{SR} 31^{320} \mathrm{SR} 33^{1020} \mathrm{SR} 36^{1070} \mathrm{SR} 36^{670}$ \\
\hline
\end{tabular}

Based on the polymorphism of ISSR markers, a matrix of Dice similarity indices was constructed (Table 4). Among hybrid progenies and the parental forms (excluding $A$. juvenalis), the greatest genetic similarity of 0.96 was between entries \#2 and \#3 (see Table 4 ) and the lowest (0.84) between the paternal line (Lanca x L506/79) x CZR142/79 of the first hybrid combination and entry \#6 from the second hybrid combination. Taking into account all hybrids and parents (including $A$. juvenalis), the least genetic similarity $(0.30)$ was between A. juvenalis and the triticale paternal hybrid form (Lanca x L506/79) x CZR142/79 (Table 4).

A. juvenalis had the least genetic similarity to all accessions studied: it ranged from 0.30 to 0.35 (Table 4 ), with an average of 0.33 . The greatest average genetic similarity to all 
the other accessions was for entry \#4. The mean genetic similarity of all the materials studied was 0.77 .

The dendrogram of genetic relationships between the genotypes studied was constructed on the basis of the similarity matrix obtained by the UPGMA method (Figure 1). The dendrogram showed three main clusters. Entries from two cross-combinations were separated and formed individual clusters. Of the hybrid strains studied, only accession \#1 did not cluster with the other three accessions from this combination or with the accessions of the second hybrid combination, but it associated with its own paternal form (Lanca x L506/79) $x$ CZR142/79, indicating that the backcross process was successful. Predictably, A. juvenalis was the least similar to all other entries tested (Figure 1).

Table 4. Dice coefficient similarity matrix based on the polymorphism of ISSR markers.

\begin{tabular}{|c|c|c|c|c|c|c|c|c|c|}
\hline & $\mathrm{Aj}$ & A & 1 & 2 & 3 & 4 & B & 5 & 6 \\
\hline A & 0.297 & & & & & & & & \\
\hline 1 & 0.317 & 0.940 & & & & & & & \\
\hline 2 & 0.325 & 0.883 & 0.871 & & & & & & \\
\hline 3 & 0.339 & 0.893 & 0.880 & 0.958 & & & & & \\
\hline 4 & 0.336 & 0.895 & 0.875 & 0.940 & 0.948 & & & & \\
\hline B & 0.328 & 0.864 & 0.873 & 0.851 & 0.861 & 0.863 & & & \\
\hline 5 & 0.343 & 0.886 & 0.902 & 0.858 & 0.868 & 0.899 & 0.875 & & \\
\hline 6 & 0.338 & 0.842 & 0.850 & 0.850 & 0.853 & 0.884 & 0.889 & 0.911 & \\
\hline 7 & 0.349 & 0.868 & 0.877 & 0.855 & 0.858 & 0.882 & 0.879 & 0.923 & 0.945 \\
\hline
\end{tabular}

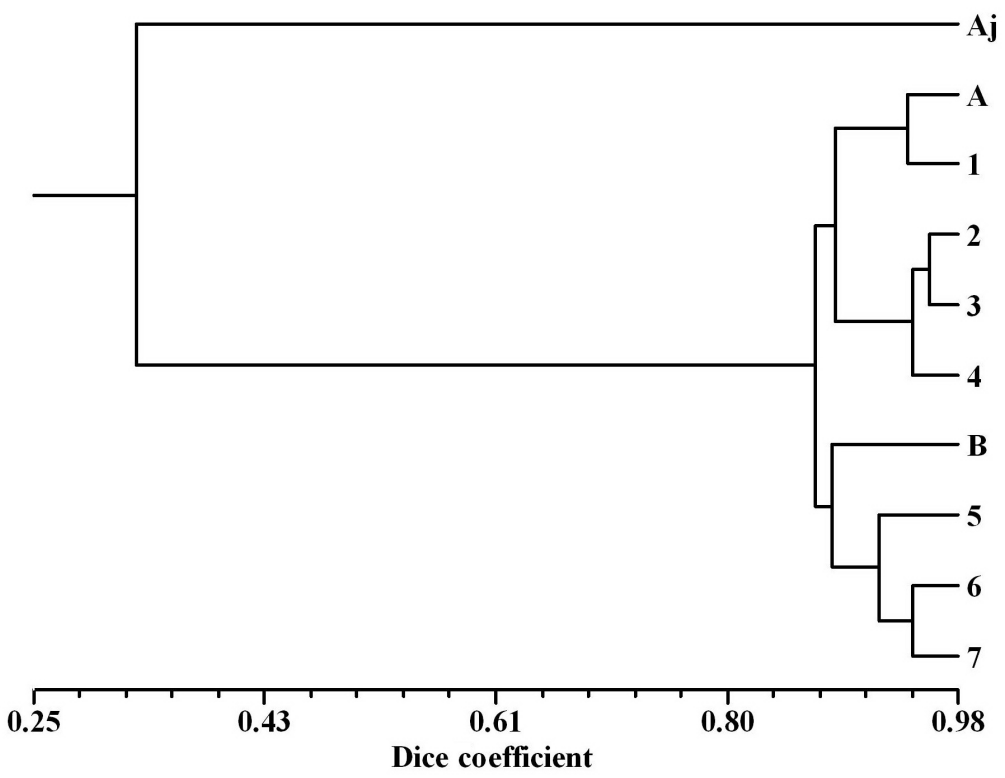

Figure 1. UPGMA dendrogram of Triticale hybrids based on the ISSR markers. Aj = Aegilops juvenalis (Thell.) Eig; A = paternal form (Lanca $\times$ L506/79) $\times$ CZR142/79; B = maternal form (Jana $\times$ Tempo) $\times$ Jana; 1-7 = hybrid strains. 


\section{DISCUSSION}

The ISSR method is often used in plant genetics. It is relatively easy and as fast as RAPD, but in contrast to the latter, it is highly reproducible and tends to uncover far more polymorphism. This method has often been applied to studies of genetic diversity in triticale, rye and wheat, including the identification of the intergeneric hybrids.

Stojałowski and Góral (2002) identified triticale cultivars and male sterile lines using only seven ISSR primers. These generated 15 polymorphic fragments $(12.2 \%$ of the total fragments generated), which clearly identified all genotypes tested. Matos et al. (2001), using polyacrylamide gels in a study of 10 rye cultivars, observed an abundance of 280 ISSR markers with only 9 primers. Similarly, a great number of polymorphic ISSRs on a polyacrylamide gel were shown by Galaev et al. (2004), who sought intergeneric polymorphism among hybrids of Triticum aestivum with Aegilops cylindrica. Again, just seven primers generated 216 polymorphic fragments, and that was $40.6 \%$ of all markers (fragments) obtained. High polymorphism of ISSRs was also shown by Bolibok et al. (2005) in rye. In 30 rye cultivars screened, up to $95 \%$ of all markers amplified using just 14 primers were polymorphic on an agarose gel, a low-resolution medium.

In this study, 72 ISSR fragments were polymorphic, amounting to $30 \%$ of all the fragments identified, also on an agarose gel. We observed a similar level of polymorphism (34\%) with both ISSRs and RAPDs, in hybrids between triticale and Aegilops crassa 4x Boiss (Gradzielewska et al., 2010). The ISSR primers amplified three to nine polymorphic ISSR fragments, with AEI of 5.1. This index was similar to that of 3.7 for RAPD and 4.4 for ISSR, when we tested triticale hybrids with $A$. crassa (Gradzielewska et al., 2010). This is in line with the results of Bolibok et al. (2005), who obtained on average 4.6 polymorphic ISSR markers amplified per primer. In turn, Stojałowski and Góral (2002) obtained between one and four polymorphic products with each ISSR primer used.

The distribution of identified polymorphisms was reflected in the PIC values. The mean value of this index for ISSR method was calculated at 0.52 . This is essentially identical to the PIC value of 0.53 that we obtained with ISSRs when testing triticale- $A$. crassa hybrids (Gradzielewska et al., 2010) and comfortably close to the highest PIC value that Powell et al. (1996) observed using four screening methods in soybean (AFLP, RAPD, RFLP, and SSR; SSRs had a PIC of 0.60). On the other hand, Sarla et al. (2005) with ISSRs and Li et al. (2000) with SSRs determined PIC values similar to ours: 0.50 for a group of rice cultivars and 0.57 and 0.51 for Avena species and cultivars, respectively. Among winter triticale cultivars and breeding lines, the average PIC calculated on the basis of polymorphic SSR markers was also similar to the one we obtained in our study (0.54) (Tams et al., 2004). In Brazilian triticale, PIC of SSRs was calculated at 0.36 , indicating low variability in the set of 54 genotypes studied (Da Costa et al., 2007). Thus, the ISSR technique seems to reveal a similar or even higher level of polymorphism in triticale as SSRs.

In this study, the ISSRs were useful for the identification of the A. juvenalis DNA in triticale hybrids, as we have shown earlier with RAPD (Gradzielewska et al., 2009). Among 94 ISSR fragments specific to A. juvenalis, 22 confirmed the presence of its genetic material in all seven hybrid derivatives. With RAPD, only four such fragments were amplified (Gradzielewska et al., 2009). In hybrids of triticale with $A$. crassa, we obtained 20 (ISSR) and 14 (RAPD) markers identifying the genetic material of the wild parent (Gradzielewska et al., 
2010). Similarly, Galaev et al. (2004), in advanced progenies from hybrids of T. aestivum with A. cylindrica, with just seven ISSR primers, identified an impressive 19 polymorphic loci, which confirmed the introgression of $A$. cylindrica DNA into T. aestivum. In contrast, 40 pairs of primers for SSRs identified only seven introgressive SSR alleles Thus, ISSRs seem to be more effective than SSRs and RAPDs for detecting variability caused by introgression of alien genetic material into the genomes of wheat and triticale.

Our results confirm genetic affinity within the two groups of derivatives. The progenies from any of the A. juvenalis 6x x [(Lanca x L506/79) x CZR142/79] or [(Jana x Tempo) $\mathrm{x}$ Jana] x A. juvenalis $6 \mathrm{x}$ cross-combinations formed separate clusters on the dendrogram and joined with their maternal triticale parents. Interestingly, such close association could not be shown with RAPDs (Gradzielewska et al., 2009). Emel (2010) confirmed the utility of ISSRs for analyzing of genetic variation in triticale, and Stojałowski and Góral (2002) also found their advantage over ISSRs.

On the basis of the matrix of Dice genetic similarities, A. juvenalis was on average the least similar to the hybrids and the triticale parents, with GS of 0.33 , as expected. A similar value was calculated for RAPDs (0.39; Gradzielewska et al., 2009). On the other hand, the highest mean affinity estimated in this study by means of ISSR and in another study by means of RAPDs (Gradzielewska et al., 2009) was shown by entry \#4 from A. juvenalis 6x x [(Lanca $x$ L506/79) x CZR142/79] with GS at 0.84 and 0.85, respectively. Both techniques showed the greatest genetic similarity calculated at 0.96 (ISSRs, in this study) and 0.97 (RAPD, Gradzielewska et al., 2009) between entries \#2 and \#3.

Based on the results of this study, the utility of ISSRs for estimations of genetic similarity of hybrids between triticale and $A$. juvenalis and for identification of interspecific (intergeneric, actually) introgressions was confirmed. Just two ISSR primers were capable of identifying the $A$. juvenalis DNA fragments in each of the seven hybrid progenies, a feat impossible with RAPDs (Gradzielewska et al., 2009).

\section{ACKNOWLEDGMENTS}

We would like to thank Prof. Adam J. Lukaszewski (Department of Botany and Plant Sciences, University of California, Riverside, USA) and Dr. Grzegorz Maziarczyk (Catholic University of Lublin, Lublin, Poland) for taking time to read and comment on the language of the text.

\section{REFERENCES}

Bolibok H, Rakoczy-Trojanowska M, Hromada A and Pietrzykowski R (2005). Efficiency of different PCR-based marker systems in assessing genetic diversity among winter rye (Secale cereale L.) inbred lines. Euphytica 146: 109-116.

Da Costa CT, Albuquerque ACS, Do Nascimento A Jr and Marcelino FC (2007). Genetic diversity of Brazilian triticales evaluated with genomic wheat microsatellites. Pesq. Agropec. Bras. 42: 1577-1586.

Emel S (2010). Evaluation of ISSR markers to assess genetic variability and relationship among winter triticale (X Triticosecale Wittmack) cultivar. Pak. J. Bot. 42: 2755-2763.

Fernandez E, Figueiras M and Benito C (2002). The use of ISSR and RAPD markers for detecting DNA polymorphism, genotype identification and genetic diversity among barley cultivars with known origin. Theor. Appl. Genet. 104: 845-851.

Galaev AV, Babaiants LT and Sivolap I (2004). Detection of the introgression of genome elements of the Aegilops cylindrica host. into the Triticum aestivum L. genome by ISSR and SSR analysis. Genetika 40: 1654-1661. 
Gonzales JM, Jouve N, Gustafson JP and Muniz LM (2002). A Genetic Map of Molecular Markers in C Triticosecale Wittmack. Proceedings of the 5th International Triticale Symposium, Radzików, 85-93.

Goyali JC, Dhindsa GS, Sohu VS and Dhindsa JS (2002). Response to Water Stress at Different Stages of Plant Growth in Triticale. Proceedings of the 5th International Triticale Symposium, Radzików, 201-204.

Góral T (2006). Evaluation of resistance of winter wheat and winter triticale breeding lines to Fusarium head blight caused by Fusarium culmorum and resistance of winter triticale to powdery mildew (Blumeria graminis) in 2005. Short Communication. Biuletyn Instytut Hodowli I Aklmatyzacji Roslin 242: 79-88.

Gradzielewska A (2006a). The genus Dasypyrum - part 1. The taxonomy and relationships within Dasypyrum and with Triticeae species. Euphytica 152: 429-440.

Gradzielewska A (2006b). The genus Dasypyrum - part 2. Dasypyrum villosum - a wild species used in wheat improvement. Euphytica 152: 441-454.

Gradzielewska A, Gruszecka D and Lesniowska-Nowak J (2009). RAPD method in examinations of hybrids of triticale and Aegilops juvenalis (Thell.) Eig. Acta Agroph. 14: 591-602.

Gradzielewska A, Gruszecka D and Paczos-Grzeda E (2010). Evaluation of hybrids between triticale and Aegilops crassa 4x Boiss applying RAPD and ISSR methods. Folia Pomer. Univ. Technol. Stetin. 276: 19-30.

Gruszecka D (1998). Transfer of Genes from Aegilops sp. to x Triticosecale Wittmack - Analysis of Some Quantitative Traits. Proceedings of the 4th International Triticale Symposium Red Deer, Alberta, 17-20.

Gruszecka D and Kowlaczyk K (2002). Yield Structure of Triticale Strains Achieved Due to Crossbreeding with Aegilops. Proceedings of the 5th International Triticale Symposium, Radzików, 345-349.

Gruszecka D, Kulpa D and Makarska E (2004). Evaluation of grain technological quality of x Triticosecale Wittmack with Aegilops sp. hybrids. Int. Agrophysics 18: 127-132.

Holoubec V, Hanusova R and Kostankova E (1992). The Aegilops collection in the Praha-Ruzyne (Czechoslovakia) Gene Bank: collecting evaluation and documentation. Hereditas 116: 271-276.

Holoubec V, Havlickova H, Hanusova R and Kostankova E (1993). Evaluation of Aegilops for aphid infestation, rust and powdery mildew resistance and seed quality. Biodiv. Wheat Improv. 15: 375-384.

Kantety RV, Zeng XP, Bennetzen JL and Zehr BE (1995). Assessment of genetic diversity in dent and popcorn (Zea mays L.) inbred lines using inter-simple sequence repeat (ISSR) amplification. Mol. Breed. 1: 365-373.

Kimber G and Feldman M (1987). Wild Wheat: An Introduction. Special Report 353, College of Agriculture, University of Missouri, Columbia.

Li CD, Rossnagel BG and Scoles GJ (2000). The development of oat microsatellite markers and their use in identifying relationships among Avena species and oat cultivars. Theor. Appl. Genet. 101: 1259-1268.

Masłowski J, Gruszecka D and Tarkowski C (1997). Tolerance of hybrids between triticale and Aegilops towards toxic aluminium ions. Folia Univ. Agric. Stetin. 175: 255-258.

Matos M, Pinto-Carnide O and Benito C (2001). Phylogenetic relationships among Portuguese rye based on isozyme, RAPD and ISSR markers. Hereditas 134: 229-236.

Milligan BG (1992). Plant DNA Isolation. In: Molecular Analysis of Populations: A Practical Approach (Hoezel AR, ed.). IRL at Oxford University Press, Oxford, 59-88.

Nagaoka T and Ogihara Y (1997). Applicability of inter-simple sequence repeat polymorphism in wheat for use as DNA markers in comparison to RFLP and RAPD markers. Theor. Appl. Genet. 94: 597-602.

Nei M (1973). Analysis of gene diversity in subdivided populations. Proc. Nat. Acad. Sci. U. S. A. 70: 3321-3323.

Nei M and Li WH (1979). Mathematical model for studying genetic variation in terms of restriction endonucleases. Proc. Nat. Acad. Sci. U. S. A. 76: 5269-5273.

Pejic I, Ajmone-Marsan P, Morgante M and Kozumplicck V (1998). Comparative analysis of genetic similarity among maize inbred lines detected by RFLPs, RAPDs, SSRs, and AFLPs. Theor. Appl. Genet. 97: 1248-1255.

Powell W, Morgante M, Andre C and Hanafey M (1996). Comparison of RFLP, RAPD, AFLP and SSR (microsatellite) markers for germplasm analysis. Mol. Breed. 2: 225-238.

Reddy MP, Sarla N and Siddiq EA (2002). Inter simple sequence repeat (ISSR) polymorphism and its application in plant breeding. Euphytica 128: 9-17.

Rohlf FJ (2001). NTSYS-pc Numerical Taxonomy and Multivariate Analysis System, Version 5.1. Exeter, Setauket, New York.

Sarla N, Neeraja CN and Siddiq EA (2005). Use of anchored (AG) $)_{n}$ and (GA) primers to asses genetic diversity of Indian landraces and varieties of rice. Curr. Sci. 89: 1371-1381.

Stojałowski S and Góral H (2002). The use of RAPD and ISSR markers for differentiation of CMS-lines of winter triticale with T. timopheevi cytoplasm. Folia Univ. Agric. Stetin. 228: 161-166.

Tams SH, Melchinger AE, Oetler G and Bauer E (2002). Assessment of Genetic Diversity in European Winter Triticale 
Using Molecular Markers and Pedigree Data. Proceedings of the 5th International Triticale Symposium, Radzików, 95-103.

Tams SH, Bauer E, Oettler G and Melchinger AE (2004). Genetic diversity in European winter triticale determined with SSR markers and coancestry coefficient. Theor. Appl. Genet. 108: 1385-1391.

Vaccino P, Banfi R, Corbellini M and De Pace C (2010). Improving the wheat genetic diversity for end-use grain quality by chromatin introgression from the wheat line relative Dasypyrum villosum. Crop Sci. 50: 528-540.

Vaillancourt A, Nkongolo KK, Michael P and Mehes M (2008). Identification, characterisation, and chromosome locations of rye and wheat specific ISSR and SCAR markers useful for breeding purposes. Euphytica 159: 297-306.

Woś H, Metzger RJ, Łukaszewski AJ and Cygankiewicz A (2002). The Effect of the D-genome Chromosome Substitutions and of Translocations of Chromosome 1D on Some Quality and Agronomic Parameters of Winter Triticale. Proceedings of the 5th International Triticale Symposium, Radzików, 59-69.

Zamorski C and Schollenberger M (1995). Occurence of diseases of triticale in Poland. Biuletyn Instytutu Hodowli $i$ Aklimatyzacji Roslin 195/196: 197-208.

Ziętkiewicz E, Rafalski A and Labuda D (1994). Genome fingerprinting by simple sequence repeat (SSR)-anchored polymerase chain reaction amplification. Genomics 20: 176-183. 